\title{
A CRIMINOLOGIA MARXISTA DE RUSCHE E KIRCHHEIMER
}

RESUMO: Este trabalho tem como objetivo apresentar as principais contribuições da obra Punição e estrutura social, de Georg Rusche e Otto Kirchheimer, publicada em 1939, assim como do artigo publicado por Georg Rusche, Arbeitsmarkt und strafvollzug (Mercado de trabalho e sistema penal), que a antecede e fundamenta teoricamente, e em conjunto inauguram a criminologia marxista. Por meio de uma pesquisa bibliográfica, pretende-se fazer uma contextualização histórica do momento em que o livro foi escrito, que influenciou de maneira relevante no seu resultado final, e também apresentar as inovações trazidas, os principais conceitos desenvolvidos e heranças teóricas, assim como as suas limitações e equívocos.

Palavras-chave: Criminologia marxista. Punição e estrutura social. Arbeitsmarkt und strafvollzug. Georg Rusche. Otto Kirchheimer.
ABSTRACT: This paper aims to present the main contributions of the work, "Punishment and Social Structure" (1939), by Georg Rusche and Otto Kirchheimer, as well as an article published by Georg Rusche, Arbeitsmarkt and Strafvollzug (The Labour Market and Penal System), which precedes and theoretically bases it, and which together inaugurate Marxist Criminology. Through bibliographical research, the intente is to recreate the historical context of the moment in which the book was written, which in a relevant way influenced the final results; to also present its innovations, the principal concepts developed, and its theoretical inheritances, and also its limitations and misunderstandings.

Keywords: Marxist Criminology. Punishment and Social Structure. Arbeitsmarkt und strafvollzug. Georg Rusche. Otto Kirchheimer.

${ }^{1}$ Doutoranda em Ciências Criminais pela PUC/RS. Mestra em Ciências Jurídicas pela UFPB. Especialista em Direitos Humanos, Econômicos e Sociais pela UFPB e ESMA/PB. Especialista em Ciências Criminais pelo Centro Universitário de João Pessoa. Bacharel em Ciências Jurídicas e Sociais pela UFPB. 


\section{INTRODUÇÃO}

Punição e estrutura social, publicada em 1939, por Georg Rusche e Otto Kirchheimer, é considerada a obra inaugural da criminologia marxista. Tal contribuição também pode ser situada no campo do que se convencionou chamar de criminologia radical, isto é, de uma criminologia que se propõe a fazer uma análise da questão criminal dentro de uma crítica ampla da sociedade e que reivindica mudanças sociais profundas.

A proposta feita por Rusche e Kirchheimer foi inovadora por relacionar a punição ao contexto econômico, mostrando que os castigos variam conforme o meio de produção no qual uma sociedade se insere e, também, por ter um caráter abertamente deslegitimante do sistema penal.

Este trabalho pretende fazer uma exposição geral da obra, tanto fazendo uma contextualização histórica do momento em que foi escrita, quanto apresentando as inovações trazidas, os principais conceitos desenvolvidos e as suas limitações e equívocos.

Além de destrinchar o conteúdo de Punição e estrutura social, também se considerou importante fazer o resgate de um artigo de autoria de Georg Rusche, de 1933, Arbeitsmarkt und strafvollzug (Mercado de trabalho e sistema penal), no qual contém a tese principal do que veio a ser trabalho depois em 1939, na obra em parceria com Kirchheimer. Esse artigo é de crucial importância para entender os aspectos teóricos da obra seguinte, tendo em vista que esse referencial não fica tão evidente nesta, por se preocupar mais em fazer uma narração histórica dos métodos penais.

Assim, na primeira parte deste trabalho é feita uma contextualização histórica da obra de Rushe e Kirchheimer, pois o período em que ela foi elaborada influenciou sobremaneira o seu resultado final, e também mostra como ela se insere dentro de uma interpretação marxista da sociedade. Na segunda parte, são apresentados seus principais conceitos teóricos, como a lei da menor exigibilidade e a relação entre mercado de trabalho e punição, assim como a narração histórica dos métodos penais desenvolvida pelos autores. Por último, sãos expostos os limites dessa teoria, bem como suas principais contribuições para o estudo da criminologia hoje. 


\section{PUNIÇÃO E ESTRUTURA SOCIAL - ASPECTOS HISTÓRICOS E PRESSUPOSTOS MARXISTAS}

Punição e estrutura social foi a primeira obra que propôs uma análise aprofundada do poder punitivo no campo do marxismo. Até então, ensaios anteriores de orientação marxista, como o do holandês Willen Bonger, tinham caráter meramente etiológico, ainda se circunscrevendo a analisar as causas do delito (ZAFFARONI, 2013).

Para David Garland (1999), a tradição iniciada por esse trabalho, que posteriormente influenciará tantas outras, é a que melhor articula os determinantes econômicos e políticos da política penal, o papel das instituições penais nas estratégias de domínio de classe e as maneiras em que a penalidade serve para expressar tanto simbólica como materialmente o poder do Estado.

Antes de se adentrar em seus aspectos teóricos, o que será feito no momento seguinte deste artigo, fez-se necessário explicitar os aspectos históricos conturbados no qual nasceu a obra, que repercutiram sensivelmente no seu resultado final, assim como expor sua inserção dentro de uma proposta mais ampla de interpretação marxista da sociedade.

\subsection{Aspectos históricos}

O livro Punição e estrutura social foi uma proposta feita por Georg Rusche ao Instituto de Pesquisas Sociais de Frankfurt ${ }^{2}$ de estudar, dentro do campo da crítica social, a relação entre mercado de trabalho e execução penal (ZAFFARONI, 2013; NEDER, 2004).

Em 1931, Georg Rusche já havia submetido uma proposta de pesquisa a respeito da relação entre punição e mercado de trabalho ao Instituto, na qual rendeu uma publicação em 1933, Arbeitsmarkt und strafvollzug (Mercado de trabalho e sistema penal), que já conteria a tese principal do que veio a ser trabalhado posteriormente com Kirchheimer (NEDER, 2004; MELOSSI, 1978).

O autor começaria a escrever Punição e estrutura social ainda na Europa, enquanto o Instituto era transferido para Nova York, fugindo da perseguição do nazismo. Rusche,

\footnotetext{
${ }^{2}$ Mais conhecido como Escola de Frankfurt.
} 
então, enviou seus escritos para os Estados Unidos, porém o Instituto considerou que ele deveria ser retrabalhado e atualizado para o período contemporâneo. Como Rusche não podia fazê-lo, solicitou-se essa tarefa a Otto Kirchheimer, que deveria completar as análises da obra. Este, que tinha conhecimentos de direito e criminologia, atualizou o trabalho acrescentando os períodos nazistas e fascistas, reescreveu toda a parte feita por Rusche e depois a traduziu. Isso foi feito sem total aprovação de Rusche e, por esse motivo, a versão final da obra tem duas partes diferentes (ZAFFARONI, 2013; NEDER, 2004; MELOSSI, 1978).

O livro foi a primeira obra da Escola de Frankfurt após sua transferência para os Estados Unidos e a primeira publicação da Escola a ser divulgada em inglês (MELOSSI, 1978). Apesar disso, ele só veio a adquirir importância trinta anos depois da sua publicação, quando foi recuperado pelo movimento da criminologia crítica e reeditado e traduzido em vários idiomas (ZAFFARONI, 2013).

Nesse meio tempo, na criminologia estadunidense, apenas dois manuais mencionaram a existência da obra, no New horizons in criminology (1943), de Barnes e Teeters, e em Principles of criminology (1947), de Edwin Sutherland. Enquanto Sutherland apenas o listou como uma sugestão de leitura, Barnes e Teeters reconheceram a importância do livro em dar uma ideia mais clara sobre como a mudança social e do sistema econômico poderia alterar fundamentalmente as maneiras de pensar e agir em relação ao crime e à punição (DOD et al, 1978).

O único criminólogo americano a empregar a tese desenvolvida por Rusche e Kirchheimer foi Thorsten Sellin, em Pioneering in penology, de 1944, e na sua obra de 1976, chamada Slavery and the penal system (DOD et al, 1978).

No Brasil, Punição e estrutura social ficou conhecida primeiramente com a citação feita pelo economista Maurice Dobb, que destacou em A evolução do capitalismo os aspectos históricos ao processo de constituição do mercado de trabalho na Inglaterra na transição para o capitalismo. Esse trabalho, no entanto, não tocava na questão carcerária (NEDER, 2004).

A segunda referência importante à obra, que a faz ser conhecida no Brasil, é feita por Michel Foucault, em Vigiar e Punir, de 1975, publicado em 1977 em português. 
Punição e Estrutura Social forneceu ideias fundamentais para a concepção de disciplina e tecnologias do controle social elaborada pelo autor, ao argumentar que as similaridades de regime, organização e estrutura que vinculam a fábrica e o cárcere devem ser compreendidas como consequência de uma sobreposição estratégica e de uma função inter-relacionada, ou seja, que as instituições penais devem ser vistas em suas interrelação com outras instituições e com aspectos não penais da política social (NEDER, 2004; GARLAND, 1999).

Outro fator favorável à disseminação da obra foi a influência de Alessandro Baratta na Criminologia brasileira ${ }^{3}$, que tanto por seu livro Criminologia critica e critica del diritto penale e de sua docência em Saarland na Alemanha, foi responsável pela divulgação do livro (NEDER, 2004).

\subsection{A obra e o marxismo}

Quando Max Horkheimer foi nomeado diretor do Instituto de Pesquisas Sociais de Frankfurt, em 1931, tornou como objetivo da Escola o empreendimento de pesquisas que fizessem uma ampla crítica à sociedade burguesa, principalmente no momento de transição do capitalismo competitivo para o capitalismo monopolista. A intenção era perseguir uma pesquisa social que integrasse a perspectiva holística de Marx na análise da totalidade dos fatos sociais, repensando e renovando a tradição marxista (MELOSSI, 1978).

A pesquisa de Rusche e Kirchheimer se insere nessa perspectiva, buscando proporcionar uma leitura materialista marxista da cultura burguesa mediante a análise das superestruturas da vida social, localizando a questão da prisão dentro de um projeto social mais amplo. Esse intuito já é evidente no artigo de Rusche de 1933, Arbeitsmarkt und strafvollzug (Mercado de trabalho e sistema penal). Esse trabalho, que apresenta a tese depois desenvolvida em Punição e Estrutura Social, ainda no seu início propõe um estudo criminológico que considere as relações materiais da sociedade e o contexto histórico, conforme trecho a seguir, da sua tradução em inglês:

certamente, a mais recente criminologia, em parte estimulada pela psicanálise, tem produzido insights valiosos sobre as causas individuais e sociais do crime e

\footnotetext{
${ }^{3} \mathrm{Na}$ qual Nilo Batista foi um de seus primeiros representantes.
} 
sobre as funções sociopsicológicas da punição. Porém esses estudos não se fundamentam nos princípios do conhecimento sociológico. Eles não estão ligados à teoria econômica, nem estão orientados historicamente. No lugar disso, sugerem uma estrutura social fixa que não existe na realidade $e$, inconscientemente, caracterizam o sistema social como eterno e imutável, e não como um processo histórico. [...] A função social do crime e da justiça criminal pode ser compreendida muito além dessas pesquisas, se simples axiomas da teoria econômica forem utilizados e não se pressupor um sistema de classes mais ou menos estático e a-histórico (RUSCHE, 1978, p. 3, tradução livre) ${ }^{4}$.

Apesar de a opção por uma análise materialista marxista implicar num compromisso com o determinismo econômico, é importante salientar que Rusche, ainda em Arbeitsmarkt und strafvollzug, não pretendia fornecer uma explicação geral para explicar o fenômeno do crime e do controle criminal, entendendo que existem várias forças que influenciam a questão, como a religião e a sexualidade. Isso pode ser claramente compreendido com a citação que segue.

\begin{abstract}
Embora circunstâncias altamente complexas e de alguma forma independentes influenciem o campo da criminologia, especialmente os aspectos biológicos e psicológicos, ainda assim a teoria econômica e a observação histórica podem esclarecer diversas questões. A dependência do crime e do controle do crime das condições econômicas e históricas, no entanto, não fornece uma explicação totalizante. Essas forças não determinam sozinhas o objeto da nossa investigação e por si mesmas são limitadas e incompletas de várias maneiras. Por exemplo, o sistema penal e o rito processual criminal são moldados por diversas forças, incluindo religiosas e sexuais. De maneira similar, nosso método de investigação não é suficiente para explicar o destino de um indivíduo singular que se torna um criminoso e sua punição em particular. Mas, dentro desses limites, certos mecanismos podem ser descobertos pela análise econômico-histórica com certa precisão (RUSCHE, 1978, p. 3, tradução livre). ${ }^{5}$
\end{abstract}

\footnotetext{
${ }^{4}$ Certainly the more recent criminology, partially stimulated by psychoanalysis, has produced valuable insights about the individual and social causes of crime and about the sociopsychological functions of punishment. But these studies lack a foundation in the basic principles of sociological knowledge. They are neither connected to economic theory, nor are they historically oriented. Rather, they imply a fixed social structure which does not exist in reality, and they unconsciously characterize the social system as eternal and unchanging rather than as a historical process. [...] The social function of crime and criminal justice can be clarified far beyond previous research, if simple axioms of economic theory are used and one does not presuppose a more or less static and ahistorical system of class relations.

${ }^{5}$ Although highly complex and somewhat independent circumstances influence the field of criminology, especially biological and psychological aspects, nevetheless economic theory and historical observation can clarify many questions. The dependency of crime and crime control on economic and historical conditions does not, however, provide a total explanation. These forces do not alone determine the object of our investigation and by themselves are limited and incomplete in several ways. For example, the penal system and the ritual of criminal procedure are shaped by various forces, including religious and sexual phenomena. Similarly, our method of investigation is not sufficient to explain specific fate of a single individual who becomes a criminal and his particular punishment. But, within these limits, certain mechanisms can be discovered by economic-historical analysis with sufficient accurancy.
} 
Curiosamente, mesmo o texto sendo permeado por ideias marxistas, a menção à influência da obra marxiana é raramente feita de maneira explícita. Garland (1999) supõe que isso se deva mais a uma discrição na apresentação do que a uma dúvida intelectual. Até porque nem Marx nem Engels trouxeram uma contribuição mais profunda na análise dos sistemas penais e, por essa razão, não somente Rusche e Kirchheimer, mas outros estudos marxistas da questão penal recorrem a uma teoria ampla da estrutura social e da história, construída pela tradição marxista, como base para suas análises. ${ }^{6}$

Para Garland (1999), Punição e Estrutura Social não é de maneira nenhuma, enquanto corpus de trabalho, o exemplo mais sofisticado de uma análise marxista, mas representa a versão mais sólida e completa da punição com esse marco teórico, e a que menos deve a outras tradições interpretativas, apesar de ser com frequência ignorada pelos críticos, que a consideram de um reducionismo elementar.

\section{A CONSTRUÇÃO TEÓRICA DE RUSCHE E KIRCHHEIMER}

David Garland (1999) observa que Punição e estrutura social é, sobretudo, uma narração histórica dos métodos penais, descrevendo como estes se desenvolvem desde a Idade Média até meados do século XX. Por essa característica, em grande medida a base teórica do livro se submerge abaixo da superfície de sua narração histórica e seus aspectos teóricos são descritos de maneira muito breve, em geral com uma linguagem que evita discretamente o uso de termos do vocabulário marxista.

No entanto, se se considerar o artigo Arbeitsmarkt und strafvollzug, de 1933, de Rusche, é possível reconstituir a estrutura teórica que guiou a investigação e a narração histórica de Punição e Estrutura Social, feita em parceria com Kirchheimer. Por essa razão, aqui se optou em expor os principais conceitos teóricos dessas duas obras, utilizando como

\footnotetext{
${ }^{6}$ Essas críticas têm influência, sobretudo, da crítica marxiana feita, em especial, pela Crítica do programa de Gotha, em que Marx introduziu a análise do direito desigual burguês. Apesar do seu enfoque ser no direito civil da sociedade capitalista, a análise também serviu à crítica da justiça penal, na medida em que o sistema penal de controle do desvio revela a contradição fundamental entre a igualdade formal dos sujeitos de direito e a desigualdade substancial dos indivíduos. Nesse caso, a desigualdade substancial se manifesta em relação às chances dos integrantes da classe proletária de serem definidos e controlados como desviantes (MARX, 2012; BARATTA, 2011).
} 
esqueleto o artigo Arbeitsmarkt und strafvollzug, e ao longo da exposição se acrescentou os aprofundamentos e acréscimos feitos no livro em parceira com Kirchheimer.

Ao analisar a obra, Garland (1999) observou que as seguintes questões fundamentais são colocadas pelos autores: Por que se adota ou se rechaça certos métodos de punição de castigo em uma dada situação social? Em que medida o desenvolvimento dos métodos penais está determinado pelas relações sociais mais básicas?

Eles, portanto, irão questionar as variações das formas ou métodos penais e sua relação com situações sociais específicas, enfocando de maneira central nos determinantes para a seleção e uso de métodos penais específicos, em vez de outros possíveis problemas, tais como o funcionamento geral da penalidade ou sua promoção de efeitos morais, o que torna essa teoria inovadora (GARLAND, 1999).

\subsection{A lei da menor elegibilidade}

Para Rusche (1933), a pena apelaria para a racionalidade das pessoas, que prefeririam não cometer uma conduta considerada crime porque antecipariam o futuro sofrimento de uma hipotética punição, o qual superaria o possível prazer de infringir determinada conduta proibida.

O autor compreende que o crime pode ser cometido por pessoas de todas as classes, mas constata que ele em sua maioria é cometido por pessoas dos estratos que sofrem mais pressões sociais por não conseguirem satisfazer suas necessidades mais básicas - apesar de considerar que a maioria das pessoas em geral são moldadas psicologicamente de forma a aceitar sua condição social. Assim, para a sanção penal ser eficiente ela precisa ser configurada de uma maneira que as classes que são mais propensas a cometer crimes prefiram se abster de cometer atos proibidos.

Se as sanções penais são feitas para deter os mais pobres, as punições devem ser feitas de uma maneira que coloque essas pessoas numa situação mais degradante do que a que elas já vivem, de forma que a pena seja menos atraente e, portanto, menos elegível, pelas pessoas das classes mais baixas.

Por isso que todos os esforços de reforma das punições criminais são, inevitavelmente, limitados pela situação das pessoas das classes mais marginalizadas da 
classe proletária. Só assim o propósito da pena pode ser preservado. Esse raciocínio feito por Rusche, inspira-se também na afirmação de George Bernard Shaw, que se reproduz a seguir:

quando vamos aos mais pobres e oprimidos da nossa população, achamos as condições de vida deles tão miseráveis, que seria impossível conduzir uma prisão humanizada, sem fazer com que a opção criminosa seja mais elegível do que aquela dos cidadãos livres. Se a prisão não oferece menos que os barracos em miséria humana, os barracos esvaziariam e a prisão lotaria (SHAW apud RUSCHE, 1978, p. 4, tradução livre) $)^{7}$.

Rusche (1933) toma o cuidado de esclarecer que essa análise é abstrata e formal, e que, apesar de poder ser verificada com frequência, naturalmente não pode se considerar que ela irá se reproduzir exatamente da mesma maneira que ele a descreveu. Isso é apenas um princípio de investigação, um guia para se abordar o assunto. Não se pode desconsiderar que existem eventos peculiares e imprevisíveis que poderão se entrelaçar de maneira inusitada e que poderão determinar também o curso da vida concreta das pessoas.

\subsection{A relação entre mercado de trabalho e punição penal}

Já que as sanções penais perseguem sobretudo as classes mais baixas, pois estas seriam as mais propensas ao crime, Rusche (1933) tenta esclarecer como as categorias econômicas determinam o destino dessas classes. Considerando que as pessoas que vivem à margem não têm uma quantidade de bens sobrando, mas apenas têm a habilidade de vender sua mão de obra, o mercado de trabalho é uma categoria determinante para definir o destino dos mais pobres.

Sendo assim, se há um mercado de trabalho escasso, os pobres não têm de onde tirar o seu sustento, a não ser recorrendo a maneiras alternativas, e o crime é uma delas. Dessa forma, se há uma massa de desempregados que poderia por necessidade ficar mais propensa a cometer delitos, esta apenas deixaria de cometê-los sob penalidades cruéis.

\footnotetext{
${ }^{7}$ When we get down to the poorest and most oppressed of our population we find the conditions of their life so wretched that it would be impossible to conduct a prison humanely without making the lot of the criminal more eligible than that of many free citizens. If the prison does not underbid the slum in human misery, the slum will empty and the prison will fill.
} 
Por outro lado, se o mercado procura trabalhadores, mas estes estão em falta, a penalidade ganha outro significado. Quando existem poucos trabalhadores, os salários aumentam, então as penas servem para sugarem mão-de-obra barata dos presos, para que eles façam serviços que os proletários livres não querem fazer, de maneira mais lucrativa e, também, ensina aos criminosos que agora trabalham nas prisões a no futuro se contentarem apenas com o salário do trabalho honesto.

O mercado de trabalho, portanto, e seus imperativos e flutuações são o determinante básico da punição, entende Rusche (1933), o que vem a ser ratificado na obra com Kirchheimer, de 1939. Obviamente, esclarece Rusche, que a escassez ou o excesso de trabalhadores não necessariamente determina a natureza do mercado de trabalho, pois intervenções políticas, de caráter de distribuição econômica, por exemplo, podem corrigir os males da flutuação de oferta e procura e a consequente necessidade de punição.

\subsection{A história do direito penal e sua relação com a economia}

Em Arbeitsmarkt und strafvollzug, Rusche (1933) inicia um relato histórico identificando os métodos penais específicos surgidos a partir do início da Idade Média e mostra como se pode compreendê-los em relação com as forças econômicas e fiscais. Esse relato é aprofundado exaustivamente na obra de 1939 em parceria com Kirchheimer.

David Garland (1999) esclarece que essa descrição histórica tem um alto grau de abstração e depende muito da bibliografia secundária e da historiografia disponível na década de 1920, e que, ela se apresenta mais como uma tentativa de prova de uma tese do que uma versão histórica equilibrada, tendendo a selecionar apenas o material que convém e a descartar o que não serve.

Mesmo que possa se julgar a maioria das descrições como parciais, Garland (1999) assume que existe um elemento de verdade nessa versão e que muitos de seus argumentos são persuasivos. Deve-se, portanto, encará-la com certo ceticismo, apesar de se perceber o mérito da tese apresentada.

Para Rusche (1933), a história do sistema penal é mais que uma história do desenvolvimento independente das instituições penais, como se costumava fazer, mas é a 
história das relações entre ricos e pobres. Por essa razão, ele propõe estudar a relação histórica entre leis criminais e economia, que também reproduz a história da luta de classes, e utilizar essas inter-relações para analisar o sistema prisional.

$\mathrm{Na}$ história da punição, três épocas teriam se sucedido, as quais foram caracterizadas pela prevalência de diferentes métodos de punição: a penitência e a multa foram características no início da Idade Média, que, em seguida, foram substituídas por um sistema de penas corporais cruéis e pena de morte, no final da Idade Média, e que depois foram superadas pela pena de prisão no século XVII.

No antigo sistema medieval, as penas por meio da multa e da penitência correspondiam às necessidades de uma sociedade agrária e pouco povoada. A abundância de terras livres impedia qualquer forte pressão social sobre as classes mais baixas e havia uma distribuição relativamente uniforme da riqueza entre os membros da sociedade. Em consequência, havia poucos crimes contra a propriedade, pois os custos psíquicos de cometer algum crime eram maiores do que o benefício de cometê-los e, por essa razão, os crimes motivados por ódio ou de cunho sexual eram os que predominavam. Aqui o medo da vingança era o principal elemento dissuasivo que evitava o cometimento de delitos e o crime era visto como uma ação de guerra. Por isso, o objetivo das regras era a reconciliação dos inimigos por meio de uma autoridade reconhecida pelas partes, e não o controle da criminalidade, como veio a ser em seguida.

Nos últimos períodos da Idade Média, esse quadro muda de figura. A população cresce substancialmente e as terras deixam de ser abundantes e disponíveis para todos. É nesse momento que se inicia uma separação clara entre ricos e pobres. A quantidade de trabalhadores sem propriedade reduz os salários em meio ao surgimento de um modo de produção pré-capitalista. Começa a se formar um exército de mendigos e emerge uma onda de agitação social e revoltas que culminam em guerras camponesas. Nesse período, a natureza da criminalidade muda completamente, pois os crimes contra a propriedade começam a preponderar. Aqui, as penas corporais cruéis são as mais recorrentes, tendo 
em vista que muitos dos criminosos não tinham bens para poder pagar pelo dano de seus delitos, e assim, só os mais abastados fugiam das lesões e da morte ${ }^{8}$.

No final do século XVI, as condições do mercado de trabalho de novo se modificaram. Ocorreu um período de notória escassez de mão de obra, não apenas pelas guerras e pragas que dizimaram parte da população, mas porque surgia o sistema mercantilista, que ampliou a necessidade de trabalho para dar conta do resultado da expansão do comércio, dos novos mercados e do afluxo de metais. Dada essa situação, tornou-se difícil convencer os proletários a servir aos exércitos, já que eles poderiam se manter fora deles em condições favoráveis de trabalho (RUSCHE, 1933).

A dificuldade de recrutar homens livres para o trabalho, principalmente na França e na Espanha, introduziu novas formas de castigo capazes de auferir ganhos econômicos: a escravidão nas galés, a deportação para as novas terras descobertas e a servidão penal através de trabalhos forçados. Isso deixa evidente que o método penal escolhido tinha sua razão de ser mais no seu caráter econômico do que no seu aspecto meramente punitivo (RUSCHE; KIRCHHEIMER, 1939).

Assim, nessa situação de escassez de trabalhadores, mutilar ou exterminar os trabalhadores era um desperdício. É desse desdobramento que a prisão posteriormente passa a substituir o castigo corporal e as penas de morte e promove um "humanitarismo" conveniente aos interesses econômicos (RUSCHE, 1933).

Na virada para o século XVIII, no entanto, a prisão passa a perder sua utilidade, em razão da substituição do trabalhador pela máquina, que eliminou a escassez de mão de obra, e criou um exército industrial de reserva. A condição das classes mais baixas se precarizou e as funções dissuasivas da pena perderam seu significado. Como a procura por trabalho era alta, os salários diminuíram, e não compensava mais pagar os custos de confinamento e supervisão das pessoas presas. Dessa maneira, o encarceramento já começou a se mostrar falho, pois não aterrorizava mais as massas pauperizadas. Passou-se a reivindicar o retorno das penas corporais, mas os ideais humanitários duramente

\footnotetext{
${ }^{8}$ Rusche e Kirchheimer (1939) salientam, nesse caso, que essas punições brutais não podem ser entendidas simplesmente como o sinal da crueldade primitiva de uma época, mas como um fenômeno social que está em coerência com as relações sociais dominantes nesse dado período.
} 
conquistados já não permitiam que isso fosse feito abertamente. Como consequência, a prisão, herdando a tradição do período anterior, passou a instituir o trabalho forçado e virou um verdadeiro lugar de tortura, degradando os presos física e psicologicamente, por meio de espancamentos, confinamento solitário e obrigação de cumprir trabalhos desgastantes, às vezes sem nenhum propósito.

Em contrapartida, nos Estados Unidos desse período, a abundância de terras e oportunidades durante o mercantilismo, requeriam uma quantidade de trabalhadores que não eram suficientes para dar conta de tudo que havia disponível. Por isso, o número de crimes era baixo e a prisão era suficiente para conter a população. O sistema penitenciário estadunidense também fornecia educação e permitia que o preso desenvolvesse uma série de habilidades para que ele pudesse se inserir novamente na sociedade. ${ }^{9}$

A Europa chegou a uma situação parecida com a dos Estados Unidos depois desse período e os encarceramentos reduziram com o arrefecimento da situação após a consolidação da Revolução Industrial. Novamente, iniciou-se um período de escassez de mão-de-obra agrícola, e vagabundos, criminosos e estrangeiros se tornaram valiosos para conter a baixa do momento.

No início do século XX, a punição na Europa e, em menor grau, nos Estados Unidos, deixou de estar diretamente imbricada ao processo produtivo do capitalismo, devido aos avanços tecnológicos e à oposição da mão de obra livre, que minaram a capacidade dos cárceres em operarem como unidades econômicas. A política penal começou a ser determinada por forças fiscais e econômicas indiretas (tais como as condições de vida da classe proletária e a necessidade de menor elegibilidade, mais que por preocupações produtivas imediatas). O incremento das multas e seu uso difuso para castigar certos delitos, antes punidos com o cárcere, foi a instância mais notória dessa tendência, e a generalização desse tipo de sanção no século XX se relacionou, sobretudo, com uma economia totalmente monetarizada e um nível mínimo de inclusão de parte da população (RUSCHE; KIRCHHEIMER, 1939; GARLAND, 1999).

\footnotetext{
${ }^{9}$ Segundo Rusche e Kirchheimer (1939), a preocupação religiosa em reformar os presos e salvar suas almas também foi elemento importante do entusiasmo por esse sistema penitenciário, apesar de considerarem que os imperativos econômicos eram os determinantes principais.
} 
Essas mesmas condições sociais, que asseguraram salários mais altos, benefícios sociais e um nível melhor de vida para a maioria da população trabalhadora antes de 1921, levaram a uma série de reformas sociais e penais que alteraram a natureza das prisões e difundiram o uso de medidas de reeducação, tais como os reformatórios, a liberdade condicional e a supervisão posterior, que demonstravam uma práxis mais racional e humana (RUSCHE; KIRCHHEIMER, 1939).

Punição e estrutural social conclui sua narrativa histórica repetindo a afirmação de que as políticas penais e os índices de delinquência são de fato causalmente independentes, porém ambos estão determinados pela mesma rede de condições sociais e econômicas. Por conseguinte, a única maneira de reduzir a delinquência e atingir uma política penal racional e humana é romper com o sistema de classes e com as condições econômicas que a alimentam (RUSCHE, KIRCHHEIMER, 1939). No contexto desse projeto, com seus conceitos e fundamentos marxistas, Garland (1999) considera razoável interpretar que a verdadeira reforma penal, para os autores, só se daria com o desmantelamento do sistema capitalista de classes e a construção de uma sociedade socialista.

\subsection{Os fundamentos teóricos de Rusche e Kirchheimer (Por David Garland)}

Para complementar o entendimento das propostas teóricas dos autores sobre a punição, considera-se conveniente o quadro feito por Garland (1999), que resume os fundamentos teóricos de Rusche e Kirchheimer da seguinte maneira:

1) A punição deve ser considerada um fenômeno histórico específico que está vinculado a formas particulares e concretas de vida.

2) A especificidade histórica da punição deve ser compreendida em relação com modos de produção particulares, que são os principais determinantes para a escolha da introdução de certos métodos penais em período históricos específicos.

3) Ainda que se diga que os sistemas penais estão orientados, em certa medida, ao controle do delito, os métodos de punição específicos nunca se determinam unicamente por esse objetivo, senão por forças sociais e determinações mais amplas. 
4) Um ponto teórico que não está explícito no texto de Rusche e Kirchheimer, ainda que seja crucial para sua análise, é que os sistemas penais devem ser entendidos em sua inter-relação com outras instituições e com aspectos não penais da política social. Assim, a política penal é apenas um elemento dentro de uma estratégia mais ampla para controlar os pobres, na qual as instituições como as fábricas, as oficinas e o mercado de trabalho desempenham um papel decisivo.

5) Do ponto anterior se deriva também a ideia de que o castigo deve ser visto não como uma resposta social à criminalidade dos indivíduos senão, sobretudo, como um mecanismo imbricado com a luta de classes, com a luta entre ricos e pobres, burguesia e proletariado.

6) Uma proposição básica da teoria marxista é que as relações sociais e instituições dentro de uma sociedade de classes estão tergiversadas e distorcidas pela ideologia, de maneira que sua fundamentação real fica oculta. Os autores consideram que essa distorção ideológica permite perceber o castigo com uma instituição que beneficia "a sociedade em geral" quando, de fato, sua função real é apoiar os interesses de uma classe contra a outra.

\section{LIMITAÇÕES E HERANÇA TEÓRICA}

Para Eugenio Zaffaroni (1991), a vinculação tão direta entre pena e mercado de trabalho defendida por Rusche e Kirchheimer é simplista e peca por não levar em consideração a questão do disciplinamento, questão que depois vem a ser trabalhada, principalmente, por Michel Foucault e na obra Carcere e fabbrica, de Dario Melossi e Massimo Pavarini. Simon (2013) acrescenta que assim como a interpretação da punição feita por Durkheim, Rusche e Kirchheimer consideram o castigo como mero reflexo da estrutura social na qual ele é implementado. No entanto, o "como" do punir não é bem explicado, o que só vem a ser melhor esclarecido nas citadas obras.

Garland (1999) aponta alguns problemas da obra de Rusche e Kirchheimer, especialmente em sua narração histórica, que se equivoca em diversas de suas interpretações. Um exemplo está na descrição dos autores da pena de deportação para Austrália, implementada pela Grã-Bretanha a alguns de seus criminosos, que para eles 
teria motivação meramente econômica. Nesse caso, já se constatou que a escolha desse método foi muito mais uma resposta à crise penitenciária do país na época, do que uma escolha para se obter vantagens econômicas, tendo em vista que o custo dessa viagem era de alto custo para o Estado.

Além disso, o autor salienta que os historiadores pesquisadores da área já perceberam que poucas das instituições penais realmente conseguiam obter benefícios lucros. Nessa mesma linha, quanto ao adestramento de proletários dóceis, evidências sugerem que isso acontecia mais pela intenção dos reformadores do que meramente por um reflexo das situações materiais. Isso também se aplica a questões em torno do desenho da prisão e dos detalhes sobre seus regimes, que têm preocupações que vão além do lucro, mas que eram também tanto de ordem social, quanto política e religiosa.

O autor também considera questionável a tese geral de Rusche e Kirchheimer que vincula as formas penais com o modo de produção e o nível de vida da classe proletária. Em razão de que se verifica sistemas penais variáveis em sociedades com condições econômicas parecidas e similaridades nos métodos em países socialistas e capitalistas.

Apesar de Rusche e Kirchheimer não pretenderem fazer uma explicação ampla dos fenômenos penais, como já foi explicado anteriormente, eles pecam por defenderem que sempre são as causas econômicas as mais determinantes nas questões de configuração da pena, quando já se percebe, mesmo na teoria marxista, a capacidade que forças políticas e ideológicas diversas têm de influenciar de forma independente o sistema penal.

De qualquer forma, Garland (1999) reconhece que eles demonstram um vínculo importante entre o mercado de trabalho e a política penal, assim como que o desenvolvimento em um campo pode ter repercussões no outro. Também apresenta evidências suficientes da importância das questões econômicas e financeiras nas práticas de política penal, incluindo práticas específicas e características institucionais. Acima de tudo, revela a importância da imbricação da política penal como estratégia de manejar as pessoas das classes mais marginalizadas. Assim mesmo, Punição e estrutura social é bemsucedida em abrir uma perspectiva que antes não havia sido descrita.

Para Rodrigo Ghiringhelli de Azevedo (2015), o conceito trazido pela lei da menor elegibilidade é válido para entender a razão pela qual o imaginário social brasileiro tem a 
ideia de que o interior das prisões deve ser pior que as condições encontradas na condição de liberdade, o que justificaria o descaso com a situação prisional e a visão da prisão como lugar de sofrimento e vingança.

Zaffaroni (1991), por fim, considera que o grande mérito da obra foi sua crítica ao discurso jurídico-penal, ao expor, com um considerável grau de acerto, a falsidade dos discursos que tentavam justificar a função da prisão e da pena, o que como consequência teve o caráter de aberta deslegitimação do sistema punitivo.

\section{CONSIDERAÇÕES FINAIS}

Delinear um quadro geral sobre a obra de Rusche e Kirchheimer foi importante para apresentar uma criminologia radical de cunho marxista.

Apesar das esperadas limitações dessa teoria, ela abre diversas perspectivas de pesquisa e mostra a fundamental relevância dos aspectos econômicos na formação dos sistemas penais, ainda que isso não se dê da maneira determinante como os autores originalmente pensaram.

Com isso, espera-se despertar interesses por conhecer esses clássicos da criminologia de modo a que alguns de seus pressupostos sejam revisitados e aplicados em reflexões sobre temas criminológicos.

\section{REFERÊNCIAS}

AZEVEDO, Rodrigo Ghiringhelli de. O sistema penitenciário no Brasil: déficit democrático e perpetuação da violência. In: José Geraldo de Sousa Júnior et al. Introdução crítica à justiça de transição na América Latina. Série O Direito Achado na Rua, vol. 7. Brasília: UnB/ MJ, 2015.

BARATTA, Alessandro. Criminologia crítica e crítica do direito penal: introdução à sociologia do direito penal. 6. ed. Rio de Janeiro: Revan, 2011.

DOD, Suzie; PLATT, Tony; RAY, Gerda; SHANK, Greg; TAKAGI, Paul. Editors' Introduction of Labor Market and Penal Sanctrion: thoughts on the sociology of criminal justice. Crime and social justice, no. 10, p. 2-8, 1978. 
GARLAND, David. Castigo y sociedade moderna: un studio de teoría social. Tradução de Berta Ruiz de la Concha. Cidade do México/Madri: Siglo Veintiuno, 1999.

MARX, Karl. Crítica do programa de Gotha. São Paulo: Boitempo, 2012.

MELOSSI, Dario. Introduction to the italian translation of Punishment and social structure. Crime and social justice, n. 9, p. 73-85, 1978.

NEDER, Gizlene. Nota introdutória à edição brasileira. In: RUSCHE, Georg; KIRCHHEIMER, Otto. Punição e estrutura social. 2. ed. Tradução de Gizlene Neder. Rio de Janeiro: Revan, 2004.

RUSCHE, Georg. Labour market and penal sanction: thoughts on the sociology of criminal justice (1933). Tradução de Gerda Dinwiddie. Crime and Social Justice, n. 10, p. 2-8, 1978.

RUSCHE, Georg; KIRCHHEIMER, Otto. Punição e estrutura social (1939). 2. ed. Tradução de Gizlene Neder. Rio de Janeiro: Revan, 2004.

SIMON, Jonathan. Punição e as tecnologias políticas do corpo. Sistema Penal \& Violência, v. 5, n. 2, p. 219-251, jul./dez. 2013.

ZAFFARONI, Eugenio Raúl. A questão criminal. Tradução de Sérgio Lamarão. 1. ed. Rio de Janeiro: Revan, 2013.

ZAFFARONI, Eugenio Raúl. Em busca das penas perdidas: a perda da legitimidade do sistema penal. Tradução de Vania Romano Pedrosa e Amir Lopez da Conceição. 5. ed. Rio de Janeiro: Revan, 1991. 